\title{
ESCOLA FAMÍLIA AGRÍCOLA: HISTÓRIAS CONSTRUÍDAS A PARTIR DE UMA IDEIA
}

\author{
Gilmar Vieira Freitas ${ }^{1}$
}

\section{RESUMO}

O presente artigo busca discutir a trajetória histórica das Escolas Famílias Agrícolas (EFAs), desde sua origem na década de 30. Estes Centros de Formação atendem especialmente a filhos de agricultores familiares, através da Pedagogia da Alternância e vêm cada vez mais sendo reconhecidos no cenário educacional da Educação do Campo. Implantadas desde 1969 no Brasil, as EFAs têm logrado a oportunidade de acesso à educação a adolescentes e jovens camponeses, contribuindo para o desenvolvimento social das comunidades. Utilizamos dados de pesquisa realizada entre 2013-2015, durante o curso de Mestrado em Educação do Campo, realizado na UFRB. A discussão evidencia uma construção histórica a partir de experiências concretas junto a agricultores familiares na França, Itália e Brasil, com destaque para o protagonismo da participação das famílias. Entretanto, há desafios fundantes para a continuidade das EFAs, principalmente pela ausência de financiamento seguro dessas escolas.

Palavras-chaves: Escola Família Agrícola - Pedagogia da Alternância - Educação do Campo.

\section{ABSTRACT}

This article intends to discuss the historical trajectory of the Agricultural Family Schools (EFAs), since its origins in the 1930s. Those training centers are attended by farmers's children. Those centers use the Alternanation Pedagogy and they are increasingly being recognized in the education scenario. They were implemented in Brazil since 1969, the EFAs have given the adolescents and young peasants the opportunity of education, contributing to the social development of those communities. We used data from a mastering research held between 2013 and 2015 at UFRB. The discussion shows a historical construction based on concrete experiences with farmer famillies in France, Italy and in Brazil, with emphasis on the participation of families. However, there are great challenges to the continuity of EFAs, namely the lack of funding to maintain those schools.

Keywords: Agricultural Family School - Alternation Pedagogy - Field Education.

\footnotetext{
${ }^{1}$ Mestre em Educação do Campo pela Universidade Federal do Recôncavo da Bahia (UFRB). Pedagogo do Instituto Federal da Bahia (IFBA) - Campus Brumado. E-mail: gilvifreitas@ hotmail.com
} 


\section{Introdução}

As Escolas Famílias Agrícolas (EFAs) são Centros de Formação que atuam na Educação do Campo, atendendo especialmente a filhos de agricultores familiares, através da Pedagogia da Alternância (PA). Essas escolas fazem parte dos Centros Familiares de Formação por Alternância (CEFFAs), que constituem uma articulação de redes de escolas que utilizam a PA. Esse Movimento vem crescendo e sendo cada vez mais reconhecido no cenário educacional brasileiro da Educação do Campo. Implantadas desde 1969 no Brasil, elas somavam em 2013 cerca de 264 estabelecimentos de ensino, espalhados em vinte estados da federação brasileira ${ }^{2}$ (BEGNAMI, 2013), e se constituem em um importante Movimento que tem logrado a oportunidade de acesso à educação de milhares de adolescentes e jovens camponeses, contribuindo para o desenvolvimento social de seu território.

Pretendemos no presente texto apresentar a trajetória histórica da implantação das EFAs desde sua primeira experiência na França, em 1935 aos dias atuais no Brasil, apresentando uma caminhada de construção pedagógica protagonizada pela participação dos camponeses. Trajetória que marca a construção de uma forma de ensino e que respeita os modos de vida do campo, contribuindo para o desenvolvimento local sustentável e para os sujeitos pertencentes ao território. Trazemos períodos e fatos relevantes que marcaram a história das EFAs e a partir de suas reflexões, proporcionaram o surgimento e aprimoramento da Pedagogia da Alternância, sendo moldada com os desafios experimentados e com luta por uma escola do campo.

Weffort (1989, p. 06) afirma que é o diálogo "do homem sobre o seu contorno e até sobre os desafios que o faz histórico", entendendo que não existe "educação fora das sociedades humanas e não há homem no vazio". É dessa forma que acreditamos não simplesmente estar "no mundo, mas com o mundo" aberto àquilo que a realidade tem a nos dizer (FREIRE, 1989, p. 35-39). Nesse sentido, dedicamo-nos no presente texto a apresentar a trajetória histórica da formação das EFAs desde as experiências pioneiras realizadas na França na década de 1930, a introdução dessa experiência no Brasil em 1969 e sua expansão nas décadas seguintes, bem como um panorama sistematizado mais próximo dos dias de hoje das EFAs no Brasil.

Embora esse tipo de escola tenha se adequado bem à realidade dos agricultores brasileiros, essa experiência nasce no continente Europeu, em um contexto temporal diferente, mas, ao mesmo tempo, com propósitos muito parecidos com aqueles que ainda hoje motivam a criação de novas EFAs no Brasil: a ausência de políticas e escolas que atendam às necessidades dos sujeitos do campo e que contribua para uma melhor qualidade de vida no campo.

\footnotetext{
${ }^{2}$ Esses dados consideram apenas os principais Centros Educativos: EFAs, Escolas Comunitárias Rurais e Casas Familiares Rurais/Escolas Familiares do Mar.
} 
Nesse intuito, o desenvolvimento do texto se pauta principalmente na história das EFAs: a origem na França em 1935 até sua expansão para a Itália; a história das ScuolasFamiglia na Itália e a sua implantação no Brasil em 1969 no Estado do Espírito Santo, a expansão nos demais estados brasileiros, culminando num panorama importante de escolas que atendem aos povos do campo.

\title{
Primeiros movimentos na França com as Maisons Familiale Rurales e a expansão mundial
}

Em 21 de novembro de 1935, nasciam os primeiros passos da Casa Familiar Rural, em francês "Maison Familiale Rurale" (MFRs). A história da criação da primeira experiência de MFR é reconhecidamente de grande importância para o Movimento das EFAs, pois constitui as suas bases, raízes e origens que, após perpassar todo um processo histórico, continua a fortalecer-se com maior visibilidade e crescimento no campo brasileiro, no cenário da Educação do Campo.

Segundo Nosella (2013, p. 45),

\begin{abstract}
A história das Escolas-Família é antes de mais nada a história de uma idéia, ou melhor, a história de uma convicção que permanece viva ainda hoje, contra tudo e contra todos. Foi a convicção de um homem, filho de camponês, que por toda a sua vida se comprometeu diretamente com o meio rural, vivendo pessoalmente no meio do povo do interior francês, compartilhando a mesma vida, carregando o mesmo passado de injustiça, sofrendo as mesmas pressões. Foi a idéia de uma Escola realmente para o meio rural e do meio rural; uma Escola que rompesse radicalmente com o modelo urbano, não nascida de um estudo teórico, nem de uma tese pedagógica, nem de um levantamento sociológico.
\end{abstract}

A pessoa a quem Nosella se refere na citação é o Padre francês Abbé Granereau ${ }^{3}$, um dos atores e autores principais da cena histórica das MFRs em sua gênese na França. Já desde bem jovem, Abbé Granereau já demonstrara sensibilidade e interesse pelas problemáticas enfrentadas pelo homem camponês; sentia-se incomodado com a forma como a sociedade rural era tratada pelo Estado e pela Igreja, ou melhor, como essas instituições não tratavam de seus interesses e necessidades da forma que era necessário (NOSELLA, 2013, p. 45).

As MFRs não surgem por acaso e é relevante o fato de elas não virem de uma mente brilhante do Estado que é quem historicamente pensa as políticas públicas "para o povo". As Maisons Familiales "Tiveram seus próprios promotores", a quem podemos chamar de "artesãos"; entre esses se destacaram os agricultores do interior da França (GARCÍAMARIRRODRIGA, 2010, p. 21) pela coragem de levar à frente e conduzir tal iniciativa de acordo com suas necessidades e realidades.

\footnotetext{
${ }^{3} \mathrm{O}$ padre Abbé Granereau nasceu no final do século XIX (1885), na França, e faleceu em 10 de junho de 1988. Teve uma vida dedicada às causas camponesas com forte atenção à juventude. "Foi nessa luta íntima com a terra, no trabalho de todo dia da roça que, um pouco de cada vez, entendi o grande valor e potencial existente na vida do homem do campo e também o que lhe faltava" (GRANEREAU, apud QUEIROZ, 1997, p. 41).
}

Revista Educação e Ciências Sociais, Salvador, v.1, n.1, 2018. 
O incentivo praticado pelo Estado ia contra aquilo de que necessitavam os agricultores, principalmente, os pais de família. Segundo o próprio Granereau (1969, p. 22), a concepção de projeto de vida para os alunos oriundos do meio rural disseminada pelos próprios professores do nível primário era que fossem para a cidade com afirmações do tipo: "seu filho é inteligente; não pode ser deixado na roça [...] é preciso encaminhá-lo nos estudos [...], vencerá na vida melhor que seu pai [...], conseguirá uma boa posição social" (Apud NOSELLA, 2013, p. 46).

Portanto, aos adolescentes e jovens restavam poucas opções, como indica Queiroz, analisando o contexto das origens da Pedagogia da Alternância na França:

\begin{abstract}
Os filhos de camponeses tinham que optar entre continuar os estudos e sair da família e do meio rural para as cidades ou permanecer junto à família e ao trabalho rural e interromper o processo escolar. As famílias precisavam da presença e trabalho dos filhos e ao mesmo tempo não tinham condições de mantê-los nas cidades. É essa a realidade que estava posta aos pais, aos sindicatos, cooperativas e à Igreja. A realidade social, econômica, política e educacional impunha desafios novos e exigentes às famílias rurais francesas, às suas organizações e lideranças (QUEIROZ, 1997, p. 41).
\end{abstract}

O discurso instituído pelo Estado francês daquela época desconsiderava a combinação entre o espaço camponês e o saber. Viver na "roça" significava se privar "de sabedoria, de ciência, de sucesso" e assim Nosella afirma que "mais uma vez celebrava-se o desquite entre cultura e agricultura". Tal postura (re) afirma que o saber só se produz no espaço urbano, colocando o mundo rural como feio, improdutivo, algo a se evitar. Mas e qual era o discurso e a prática da Igreja? Em tese, essa instituição se preocupava com a "educação de toda pessoa humana", no entanto, "sem nenhuma fórmula educacional capaz de responder realisticamente aos problemas da lavoura" (NOSELLA, 2013, p. 46-47).

O sindicato rural criado em 1911 pelo padre Granerau já evidenciava a sua sensibilidade e preocupação com os camponeses na intenção de coletivizá-los e de se superar o isolamento. Acreditava que juntá-los era o melhor remédio. Porém, três anos depois, sentiu que a solução iria além da questão organizacional; era preciso escola para atender à necessidade agrícola, com "uma formação capaz de preparar chefes de pequenas empresas rurais". Percebe-se notoriamente a opção do padre pelo campo, prova disso foi que, de forma espontânea, trocou uma paróquia de grande porte em uma cidade da França para exercer seu sacerdócio na pequena Sérignac-Péboudou, onde exatamente em 21 de novembro de 1935 se daria início à construção desse novo modelo de escola no contexto do campo com uma classe composta de apenas quatro alunos (GRANEREAU, 1969, p. 30; apud NOSELLA, 2013, p. 47). Porém, havia uma dificuldade: como reuni-los se eles tinham a necessidade de estar constantemente no trabalho da lavoura? (NOSELLA, 2013, p. 47). Haveriam de encontrar um caminho para esse desafio.

Além de Granerau, Jean Peyrat e Couvereur são outros dois importantes personagens para que as MFRs pudessem ser pensadas e com condições de funcionar e evoluir. $\mathrm{O}$ agricultor Jean Peyrat era um "um verdadeiro líder local" de Serignac-Péboudou, uma 
pequena aldeia da região sudoeste da França, aborda García-Marirrodriga (2010, p. 22). Exercia o cargo de presidente do Sindicato Agrícola da comunidade onde vivia e mais tarde se tornaria o primeiro Presidente da União Nacional de Maisons Familiales Rurales da França.

A liderança, sensibilidade, inquietude e insatisfação do pároco e desse agricultor frente aos problemas enfrentados no meio rural seriam importantíssimas, porém, faltava uma teoria, pensamento, metodologia para mudar aquela realidade. A motivação veio exatamente com o filho de Jean Peyrat, Yves, um pré-adolescente que tinha desistido do sonho alimentado pelo pai de cursar o ensino superior.

Segundo García-Marirrodriga (2010, p. 23-24), Yves completara doze anos quando concluíra uma etapa de estudos do programa de ensino francês, porém se sentia desmotivado para voltar à escola. O processo de escolarização daquela etapa era de cunho obrigatório e terminava com treze anos de idade. Yves estava perto de alcançar o Certificado de Estudos Primários. Saía de sua residência na segunda-feira e só retornava no fim de semana, ficando, portanto, a maior parte do tempo longe da família (ZAMBERLAN, 2003, p. 27)

Ao perceber o desânimo do filho, Jean, "começou a tomar consciência da necessidade de uma formação complementar, para atender às necessidades do filho". Sentiase decepcionado, pois havia sonhado algo diferente para ele, que tivesse mais oportunidades de uma instrução melhor do que ele mesmo teve. Esse fato o fez conversar com o padre da sua paróquia, que também militava no Sindicato e com o qual Jean tinha costume de discutir questões relevantes (GRANEREAU, 1969, apud GARCÍA-MARIRRODRIGA, 2010, p. 24; ZAMBERLAN, 2003, p. 27). Desse diálogo (narrado pelo próprio Sacerdote em 1969), nasceu a iniciativa de uma escola:

\footnotetext{
- Yves não quer ir à escola superior. É uma desgraça, porque aos doze anos ainda não acabou de se formar.

- Nem tudo está perdido. Existem outras escolas - disse o pároco. Escolas do Estado, Escolas Livres, a Escola de Marmande, por exemplo.

- Sim, tudo isso está muito bem para formar as pessoas da cidade, mas não para formar agricultores.

- Existem as Escolas de Agricultura; existe uma em Fazanes, a trinta quilômetros de tua casa.

- Quantos agricultores autênticos - prosseguiu Jean Peyrat - você tem visto sair da Escola de Agricultura? Além disso, é muito cara. Sempre acontece igual conosco: ou instruir-se, abandonar a terra e seguir desenganados, ou não abandonar a terra e continuar ignorantes por toda vida.

- Existem também cursos por correspondência...

- Isso não é mais que um paliativo que não resolve o problema.

- Mas então, e se eu mesmo fizer o trabalho?

- Ele sozinho vai se aborrecer, o remédio seria pior que a doença.

- E se encontrar outros?

- Então encontre outros, senhor padre, meu filho será o primeiro (GRANEREAU, 1969, apud GARCÍA-MARIRRODRIGA, 2010, p. 24).
}

Esse diálogo histórico é o ponto de partida, porém seria preciso pesquisar e encontrar a melhor forma e condição para que aquela ideia pudesse acontecer na prática, além de 
discussões e mobilizações junto a outros agricultores para dar vida àquela tentativa enunciada. Nesse processo de mobilização, o padre terá o papel de encorajá-los.

Em 21 de novembro de 1935, período antecedente à Segunda Guerra Mundial, oficialmente (JESUS, 2011, p. 52) nasce a primeira Casa Familiar Rural, envolvendo o padre e quatro (4) jovens (Yves Peyrat, Lucien, Paul Callewaert e Eduard Clavier), ${ }^{4}$ os "quatro pioneiros a viver essa inovação", e seus pais, sendo três (3) agricultores. Todos eles "acreditavam ser possível criar uma escola que atendesse às necessidades do meio rural e que ajudasse a ampliar as possibilidades dos conhecimentos básicos do jovem do campo" (GIMONET, 1999, p. 40).

No segundo ano de funcionamento, dezessete jovens se inscreveram; a notícia se espalhou pelas vizinhanças. Dois anos depois do início, já se somavam quarenta estudantes. Com a necessidade de estruturar melhor aquela iniciativa, criaram uma associação que unia todos os pais e financiaram uma casa com uma estrutura melhor, em outro lugar. Nascia assim em 1937 "A Casa Familiar de Lauzun (nome da pequena cidade na qual foi implantada) e contrataram um formador", a primeira Casa Familiar (GIMONET, 1999, p. 40).

[...] foram recolhendo uma quantia de dinheiro (30.000 Francos) e, no dia 25 de junho de 1937, adquiriram uma casa, na localidade de Lazun. Um mês depois, os pais foram reunidos, numa Assembléia Geral e, retomando o estatuto visto no ano anterior, o complementaram e aprovaram, dando à Associação todos os poderes jurídicos sobre a Casa Familiar Rural - CFR.” (Apud ZAMBERLAN, 2003, p. 28).

O êxito dessa iniciativa era grande, pois criaram um tipo de escola irrecusável para seus filhos, já que "ela responderia às suas necessidades fundamentais nessa idade da adolescência, ou seja, agir, crescer, ser reconhecido, assumir um lugar no mundo dos adultos, adquirir um status e papéis" (GIMONET, 1999, p. 40). Importante destacar como Gimonet (1999) vê o aspecto das necessidades do jovem. É a imagem de um jovem que também quer ser autor do processo educacional. Tais características resultam na perspectiva de participação dos jovens de alguma forma que se sintam melhor no processo, não como meros espectadores de uma aprendizagem, mas de forma proativa diante da situação coletiva ou mesmo diante de suas próprias necessidades.

A "fórmula" pensada inicialmente pelo padre e alguns agricultores foi a de que os jovens ficariam alguns dias juntos no mês, convivendo durante todo o tempo, sendo que depois voltariam para sua "propriedade agrícola". Esse planejamento agradou e decidiram implementar a ideia. Dessa forma, assim nascia a primeira escola em Alternância que por um bom tempo era chamada de a "fórmula de Lauzun" (NOSELLA, 2013, p. 47-48).

Mais do que a importante participação do padre Granereau para a implantação da MFR, García-Marirrodriga (2010, p. 23) afirma que é imprescindível valorizar mais ainda as

\footnotetext{
${ }^{4}$ Dois desses jovens eram irmãos (Lucien e Paul Callewaert), filhos do agricultor Callewaert, portanto uniamse três famílias (GARCÍA-MARIRRODRIGA, 2010, p. 25).
}

Revista Educação e Ciências Sociais, Salvador, v.1, n.1, 2018. 
razões que motivaram a criação da MFR, ou seja, "a necessidade sentida pelas famílias [...]". É importante destacar essa fala do autor porque ressalta a importância da participação das famílias no processo. Há ainda um terceiro personagem com destaque nesse processo, que contribui para a afirmação e sustento dessa experiência inicialmente. Trata-se de Arsène Couvereur, ${ }^{5}$ vice-presidente do Secretariado Central de Iniciativa Rural (SCIR), que conheceu e acompanhou a implantação da MFR pioneira. "Foi ele quem, por suas numerosas e importantes relações parisienses, facilitou os primeiros contatos dos promotores com os poderes públicos" (GARCÍA-MARIRRODRIGA, 2010, p. 23).

Para esse mesmo autor, o padre Granereau, o agricultor Peyrat e o jornalista Couvreur, "ajudados por alguns outros, foram inquestionavelmente os três pioneiros das MFR". Porém não se pode perder de vista o ponto de partida, o problema vivenciado pelo jovem agricultor Yves que "não pode suportar por mais tempo a desmotivação que lhe supõe uma escola que se adéqua muito pouco as suas aspirações" (GARCÍA-MARIRRODRIGA, 2010, p. 23).

O tempo de estadia na escola, que funcionava na paróquia, era, inicialmente, de uma semana. Dois anos após o início, esse tempo diminuiu para meia semana, por razão da dedicação dos jovens ao trabalho intenso da lavoura. Porém, em 1939, entenderam que deveriam voltar a uma semana inteira de estadia por mês, ano em que "já existiam três turmas (classes ou séries) que se revezavam" (NOSELLA, 2013, p. 48). Outro destaque é a tentativa de se ajustar à realidade vivida pelos jovens em suas propriedades.

Inicialmente, o único professor era o padre, ou podemos chamá-lo de monitor? ${ }^{6}$

\begin{abstract}
Não havia outro professor senão o padre. Os cursos não correspondiam a nenhum currículo pré-formulado: era o material, que chegava na casa do padre por correspondência, dos cursos de agricultura elaborados por um instituto católico. A única tarefa do padre era auxiliar os jovens a seguir esses cursos. O conteúdo era totalmente técnico-agrícola. A parte de formação geral nada mais era que uma reflexão informal entre os jovens e o sacerdote. Nessa reflexão, obviamente, entrava muito assunto religioso de formação humana e cultural sobre a vida do campo, sobre os valores do campo, etc. (NOSELLA, 2013, p. 48).
\end{abstract}

Posteriormente, foi contratado um técnico agrícola, seguindo o programa do curso por correspondência. Somente em torno de 1943, as "Maisons Familiales começaram a esboçar um currículo próprio e mais complexo", o que hoje as EFAs chamam de Plano de Formação (currículo escolar). Algo que podemos perceber como característico nesse início é o aspecto do internato, já que os jovens permaneciam em tempo integral durante uma semana na paróquia. A participação dos jovens alunos foi outro ponto importante na experiência das "Maisons", pois aos poucos os jovens se inseriam no meio social deles de uma forma diferente, "participando das organizações e reuniões socioreligiosas de suas

\footnotetext{
${ }^{5}$ Ex-bancário, natural de Paris, que se insere no jornalismo de grande difusão no país. Criou o "France Agricole", espaço importante de informações sobre agricultura. Foi também vice-presidente do Secretariado Central de Iniciativa Rural (SCIR) (GARCÍA-MARIRRODRIGA, 2010, p. 23).

${ }^{6}$ Por monitor, entenda-se o educador que atua nas escolas de Alternância.
} 
comunidades, procurando melhorar a situação de seu meio" (NOSELLA, 2013, p. 48-49). Valorizando esse aspecto da participação dos jovens, recorremos a Bordenave (1994, p. 16) que coloca que "a participação não é somente um instrumento para a solução de problemas, mas, sobretudo, uma necessidade fundamental do ser humano, como o são a comida, o sono e a saúde" (Apud BURGHGRAVE, 2003, p. 53).

O direcionamento da "Maison Familiale" era de responsabilidade de um grupo composto pelo padre e por pais dos estudantes. Segundo Nosella, naqueles primeiros anos, há indícios de conflitos na gestão da escola, tendo em vista que "o caráter forte do sacerdote dominava e monopolizava a ação". A busca por apoio do Governo foi uma das tarefas desse grupo e de outros, tendo em vista que até 1940. O apoio foi concedido sem dificuldades e, de certa forma, inspirou o país "na elaboração de uma lei de aprendizagem para os jovens do meio agrícola" (NOSELLA, 2013, p. 49).

Nessa mesma data, foram criadas as novas MFRs, "uma em Vétraz-Monthoux, no Estado de Rhône-Alpes (na Haute-Savoie); a outra, feminina, em Lauzun. Essa última [...] com 35 alunas [...] - vinha a realizar um antigo desejo dos responsáveis da primeira MFR" (GARCÍA-MARIRRODRIGA, 2010, p. 36). A escola criada para as meninas trabalhava na perspectiva da economia familiar e social; a dos meninos tinha um conteúdo voltado para a agricultura.

Já entre 1944 e 1945, viu-se uma incidência maior na expansão das Maisons, ao mesmo tempo em que desastrosamente a França foi ocupada pela Alemanha no início da década de 40. Diante desse cenário de crise e reestruturação da França, as Maisons foram favorecidas, sendo vistas como uma oportunidade para a retomada do país no espaço rural. Em 1942, foi criado o primeiro Centro de Formação de Monitores e a União Nacional das Maisons Familiales, unindo "cerca de quatro ou cinco" escolas (NOSELLA, 2013, p. 49$50)$.

A criação dessas duas entidades, o Centro de Formação e a União Nacional, vem na perspectiva de evitar a perda da unidade, em um momento de muitos conflitos, em que cada Maison interpretava a Alternância e o projeto da MFR de uma forma (CALIARI, 2002, p. 80). Possivelmente, essa estrutura tenha incentivado ou motivado a expansão das escolas, pois, entre 1944 e 1945, já se contavam cerca de vinte MFRs. Com a ampliação do Movimento, consequentemente, vieram também a aumentar os desafios. Uma dessas dificuldades que mexeu com a estrutura existente foi uma grande crise que permeou a União Nacional criada em 1942; a crise foi gerada por pelo menos três fatores, quais sejam:

a) $\quad \mathrm{o}$ primeiro fator está relacionado a dificuldades em gerir $\mathrm{o}$ Movimento. As famílias envolvidas cada vez mais tomavam as "rédeas" do Movimento e isso se constituiu em um conflito com o padre Abbé Granereau. Segundo Nosella (2013), o sacerdote não tinha a preocupação e aptidão para a administração daquele Movimento, de forma que agradasse os grupos envolvidos. 
Isso fez com que "Os agricultores, ao repararem isso, começaram a ter medo das possíveis consequências dessa desordem e a exigir do padre certa disciplina administrativa";

b) questões políticas envolvendo o sacerdote. Havia o desagrado de que ele não era suficientemente prudente nas suas relações políticas: "tinha-se relacionado, talvez demais, com o governo colaboracionista com os alemães". Isso indicava que fosse interessante o seu afastamento (NOSELLA, 2013, p. 50);

c) uma questão de "concepção e doutrina da Maison Familiale" (NOSELLA, 2013, p. 51), como podemos exemplificar no trecho a seguir de Nosella:

\begin{abstract}
O Sacerdote cogitava de uma escola camponesa em sentido total e extremado, sem abertura para a cidade ou para outras formas de educação. Ele queria uma formação para o campo totalmente fechada, que escolarizasse todo o sistema educacional, do primário até a universidade rural. Evidentemente, os agricultores não puderam aceitar essa concepção, porque não era possível e nem desejável que todos os jovens ficassem no campo e, até porque não seria normal fechar um grupo de pessoas do resto do País (2013, p. 51).
\end{abstract}

Esse trecho parece nos revelar algumas contradições presentes no processo das MFRs, inclusive sobre o conceito de permanência do jovem no campo, porém não fica nítido o teor das discussões. Por um bom tempo foi possível perceber a ideia de fixação do jovem no campo, lembrando o Ruralismo Pedagógico dos anos 30, o que parece ser um propósito defendido pelo padre.

O primeiro ponto destacado na crise do Movimento francês parece já ter anunciado o que seria um dos pilares das EFAs atualmente: uma associação de famílias de agricultores/as na gestão do Movimento, seja em âmbito local, regional ou nacional. Já o terceiro ponto da crise das Maisons coloca em questão o projeto político-pedagógico da escola no sentido de pensar que escola se queria naquela época.

O afastamento de Abbé Granereau do Movimento foi inevitável e a partir daí:

[...] houve uma "pedagogicização" (positiva) do movimento, isto é, foram chamados técnicos em pedagogia que começaram a estudar e sistematizar o movimento, utilizando noções de outras escolas pedagógicas, dando assim ao movimento um quadro teórico e técnico rico e científico, saindo da pura intuição e improvisação. O sacerdote e os primeiros agricultores tinham inventado a alternância, mas, para eles, isso nada mais era que uma prática, sem refletirem sobre o que isso poderia representar para a educação (NOSELLA, 2013, p. 51).

Um destaque dessa "pedagogização" é André Duffaure, ${ }^{7}$ que, entre 1946 e 1947, criou o Plano de Estudo, instrumento pedagógico utilizado ainda hoje pelas EFAs

\footnotetext{
${ }^{7}$ André Duffaure exerceu o cargo de "Diretor Geral da UNFREO, membro da FAO e de outras organizações internacionais." Destaca-se também por ser pioneiro na tentativa de sistematizar trabalhos sobre a Pedagogia
} 
(NOSELLA, 2013, p. 51-52) e considerado como o carro chefe de toda movimentação pedagógica da Pedagogia da Alternância (PA). Além desse instrumento, vieram logo também o Caderno da Realidade "e assim, os instrumentos pedagógicos" (BEGNAMI, 2003, p. 28).

A expansão das Maisons Familiales se acentua fortemente entre 1945 e 1960, passando de 30 para 500 escolas. Daí, surge a preocupação em relação a esse avanço quantitativo sob o risco de que as Maisons poderiam perder a sua essência. Para tanto, foi preciso barrar esse movimento expansivo, inclusive com o fechamento de várias escolas. Foi feita uma reestruturação organizacional do Movimento, descentralizando a organização nacional para locais e regionais. Cada organização criada tinha suas respectivas representações, acompanhando o modelo implementado na União Nacional. Dessa mesma forma, se descentralizou também o Centro de Formação de Monitores, criando vários Centros Regionais para facilitar a formação dos monitores (NOSELLA, 2013, p. 52).

Juridicamente, as MFRs se incluíam como instituição de formação profissional agrícola, como escolas de caráter privado. O primeiro reconhecimento em lei se deu em 1960 (25 anos depois do início da primeira escola em 1935), reconhecendo as MFRs como "modalidade pedagógica com a alternância". Portando, de um direito legal, veio mais reconhecimento, também um financiamento do Estado com mais segurança. Em 1984, Gimonet menciona a conquista de uma segunda lei que reforça o reconhecimento legal e o apoio do Estado francês às Escolas de Alternância (GIMONET, 1999, p. 41).

Tendo alcançado um nível de maturidade, o Movimento francês se destaca em seus passos seguintes pela participação na expansão da experiência de Alternância em outros países e continentes (GARCÍA-MARIRRODRIGA, 2010, p. 47), e também na estruturação desse Movimento em âmbito mundial. Como afirma Gimonet (1999, p. 42), nos anos 60 e 70, as Escolas de Alternância se expandem para "outros países europeus (Itália, Espanha, Portugal), no Continente Africano e, em seguida, na América do Sul, assim como no Caribe, no Oceano Índico, na Polinésia, na Ásia e, por último, na América do Norte, na província do Quebec, no Canadá".

Foi criada em 1975, em Dakar (Senegal), a Associação Internacional das Maisons Familiale Rurales (AIMFR), instituição essa que representa até a atualidade "as diferentes Instituições promotoras de Escolas de Formação por Alternância” em âmbito mundial. Cinco anos depois (1980), a AIMFR cria a Solidariedade Internacional das MFRs (SIMFR) para "dar apoio ao desenvolvimento dos CEFFA no mundo", sobretudo na formação dos monitores e na assessoria técnico-pedagógica dos CEFFAs (GARCÍA-MARIRRODRIGA, 2010, p. 48-52).

da Alternância tendo como foco a "participação dos pais nas MFR”. Falece em 1997 (ZAMBERLAN, 2003, p. 28). 
Dados de 2008 apontam para a existência de 1.325 CEFFAs distribuídos nos cinco continentes do mundo. Na Europa, registra-se a existência de 523 CEFFAs, abrangendo quatro países apenas. Nesse bojo, destaca-se a França com $88 \%$ desse total. A América supera o continente europeu com 593 CEFFAs distribuídos em 17 países. Estão no Brasil 44\% desse total e 19\% na Argentina. Na África foram contados 193 CEFFAs, em 16 países. E, por fim, 16 CEFFAs em três países da Ásia e Oceania (CALVÓ, 2010, p. 110-117).

Dentre essa expansão, queremos retomar sinteticamente a experiência da Itália, que foi crucial para fazer a Pedagogia da Alternância chegar ao Brasil.

\section{Alternância em Movimento: as Scuolas-Famiglia na Itália}

Após forte expansão na França nas décadas de 1940, 1950 e 1960, o Movimento das Maisons Familiales Rurales rompeu fronteiras internacionais. O primeiro país a receber essa expansão internacional foi a Itália incorporando outro nome: Scuola della Famiglia Rurale, de forma abreviada, Scuola-Famiglia (NOSELLA, 2013, p. 56; PESSOTI, 1978, p. 19).

Entre 1961 e 1962, nascem as primeiras Escolas-Família em chão italiano, em Soligo (Treviso) e Verona, novamente em um contexto de revoltas que envolvem o mundo agrícola, "no contexto sócio-econômico-político do após guerra" (NOSELLA, 2013, p. 56-57). A Scuola-Famiglia nasceu na Itália pelos braços políticos e por isso não se tinham dificuldades quando se tratava de apoio governamental. Metodologicamente, houve adaptação da experiência praticada na França. Nosella chama a atenção para a atuação dos monitores das Escolas-Família, cuja maioria pertencia ao Estado. Notava-se neles menos motivação com o trabalho, comparando-se aos monitores franceses (NOSELLA, 2013, p. 57). Esse início é marcado pelo intercâmbio com a experiência da França, inclusive os "primeiros monitores das escolas italianas estagiaram nas escolas francesas” (PESSOTI, 1978, p. 19-20).

No período de implantação e expansão nos anos 60, a formação ocorria com assessoria francesa, "aconteceu em diferentes EFAs, por meio de encontros anuais: semanas especiais, seminários e outros encontros que aconteciam com assessoria direta de André Duffaure e outras pessoas da União francesa das MFRs" (ZAMBERLAN, 2003, p. 32).

Até os anos 70, a Itália viveu um período crescente e de expansão; após isso, o que se viu foi o quase desaparecimento das Escolas-Família italianas (ZAMBERLAN, 2003, p. 3031). É possível de se apontar alguns motivos para esse retrocesso italiano, referente a uma pesquisa realizada na Itália:

O êxodo rural expondo a incompatibilidade dessa Escola à situação socioeconômica do campo, que exigia um profissional empreendedor; as instituições voltadas ao desenvolvimento rural que privilegiavam os conteúdos tecnológicos ligados à assistência técnica, divulgação e informação socioeconômica, em detrimento de valorizar e salvaguardar a cultura camponesa; a descentralização da formação profissional, delegada às regiões (poder público); uma excessiva burocratização das estruturas educativas em alternância, custos de gestão bastante elevados e a dificuldade de encontrar alunos, filhos de 
camponeses, durante o período do êxodo rural (SCHIOPPETTO, 1994, p.49; apud ZAMBERLAN, 2003, p. 31).

Zamberlan (2003, p. 32) traz outra evidência, a falta de um "centro ou um meio permanente de formação inicial dos monitores-docentes". Acreditamos que esse fato pode ter sido decisivo, pois, sem um processo de formação, dificilmente há um processo coletivo de avaliação, reflexão e reconstrução de um projeto político e pedagógico.

Segundo esse autor, há cerca de dez anos (início dos anos 2000), o número de unidades educacionais que utilizam a Alternância na Itália era pequeno, ressaltando a forma político-administrativa particular de cada escola "substancialmente diferentes das de outros países europeus, onde a experiência formativa familiar em alternância se difundiu e manteve alguns pilares de sustentação do início de suas atividades". É uma experiência que cabe reflexão aos outros movimentos que desenvolvem a Alternância, pois "sem envolver de fato e de direito os segmentos populares, de forma continuada e participativa poucas raízes conseguem colocar" e então será um projeto fadado ao fracasso, ao desaparecimento (ZAMBERLAN, 2003, p. 32-33).

\section{A Escola Familia Agrícola no Brasil: aspectos históricos}

A vinda das Escolas Famílias Agrícolas (EFAs) para o Brasil tem uma origem intimamente ligada à história das Escuolas-Famiglia italianas. Se na Itália a experiência é implantada através do esforço de políticos, no Brasil a implantação volta a ter o apoio e iniciativa de pessoas ligadas à Igreja, através do Padre Humberto Pietrogrande.

Durante visita desse padre ao Brasil, a partir de 1964, chamou-lhe a atenção de forma mais particular a realidade precária socioeconômica encontrada no interior do estado do Espírito Santo, onde havia maioria de descendência de italianos e alemães; uma região "caracterizada por uma ampla imigração italiana, principalmente proveniente das regiões do Veneto e da Lombardia a partir de 1875 até início do século XX" (CAVATI,1983; apud ZAMBERLAN, 2003, p. 34). Ele comparava a situação encontrada com outras regiões onde havia emigrantes, onde havia condições melhores, por exemplo, no estado do Rio Grande do Sul (RS). Essa situação o inquietou e concluiu que precisava fazer algo por aquela realidade, mas na ocasião teve que regressar a Florença para concluir a sua formação (NOSELLA, 2013, p. 61-62).

O Brasil como um todo passava por um momento de mudanças políticas e econômicas, momentos de crise que afetavam fortemente a realidade do campo. Esse período lembra a realidade vivida pela França quando surgem as Maisons Familiales, pois o contexto brasileiro era marcado pelo êxodo rural em intensidade, tornando os centros urbanos ocupados e inchados, enquanto as terras rurais ficavam esvaziadas. A cidade atraía as pessoas do campo em busca de uma "vida melhor", a industrialização crescente e a demanda por mão de obra atraíam fortemente o povo camponês. Politicamente, vivia-se o período da Ditadura Militar, marcado pela obscuridade e censura. 
De fato, o cenário não era animador para o surgimento de uma proposta educacional popular. Nesse contexto, segundo Queiroz (1997, p. 49-51), o Brasil apresenta uma situação de concentração da propriedade das terras prejudicando os pequenos agricultores, restandolhes "abandonar a terra em favor das grandes fazendas e aumento assustador do assalariamento rural". Além da concentração de terra por fazendeiros, "a violência no campo, a miséria e a fome, com a consequente degradação das condições de vidas dos trabalhadores rurais, levam a um crescente êxodo rural". Segundo esse autor, para muitos, o advento das EFAs significava "uma possibilidade de superação desses desafios".

Enfim, nascem as EFAs brasileiras. Em um contexto de abandono, com crescente "empobrecimento, desânimo, e um grande êxodo para as grandes cidades, por consequências de um modelo econômico urbano-industrial, baseado no capital, na indústria e no latifúndio, voltado para a integração do campo à indústria moderna, privilegiando a grande empresa ou transformando o campo em empresas capitalistas" (BEGNAMI, 2003, p. 30).

A EFA se implanta no meio rural em pleno regime militar, onde as políticas públicas para o campo priorizam a grande produção agropecuária, o modelo da agricultura patronal, voltado para monoculturas e ao mercado externo, com grande tendência à sofisticação tecnológica com a conseqüente liberação generalizada de mão-de-obra e a proletarização dos trabalhadores rurais (CALIARI, 2002, p. 2931; apud BEGNAMI, 2003, p. 30).

De acordo com pesquisa do Instituto Superior da Religião (ISER), na época da implantação das primeiras EFAs em terras capixabas, o estado do Espírito Santo se caracterizava por ser

\footnotetext{
predominantemente rural com $68,1 \%$ de sua população economicamente ativa ligada a atividade agropecuária, 30,9\% da área rural do Estado ocupada por matas naturais, 40,6\% dos estabelecimentos agrícolas na faixa de 20 a 40 ha, 54,\% da população rural sem instrução formal, $55,9 \%$ do pessoal ocupado em atividades agropecuárias era formado por mão-de-obra familiar não remunerada e $24,5 \%$ em regime de parceria (ISER-CARVALHO; STEIL, 1991, p. 5; apud ZAMBERLAN, 2003, p. 34).
}

$\mathrm{Na}$ Itália, Humberto Pietrogrande encontrou apoio em outros colegas padres de sua região e, então, começou a mobilizar pessoas e projetos a fim de que conseguisse condições para voltar ao Brasil e tentar intervir naquela realidade encontrada no interior do estado do Espírito Santo. Segundo Nosella, esse momento coincide com um espírito novo da Igreja, a partir do Concílio Vaticano II, que "induzia os padres a se preocuparem, não somente com uma ação sacramentalizante, mas, sobretudo, com uma ação promocional socioeconômica do povo". Cria-se então a Associazione degli Amici dello Stato Brasiliano dello Espírito Santo (AES) em 11 de dezembro de 1966, com um dos objetivos de "possibilitar a assinatura de convênios e arrecadações de recursos" (NOSELLA, 2013, p. 62-63).

Um dos primeiros êxitos dessa instituição foi conseguir apoio (bolsas de estudo) para o intercâmbio na Itália de sete jovens do interior do Espírito Santo. Segundo Nosella, não existia uma clareza do objetivo da ida desses jovens para a Itália, mas, como a AES tinha 
"contato com as Escolas-Família da Itália, achou interessante mandar os brasileiros estagiarem nessas escolas” (NOSELLA, 2013, p. 63).

Concomitantemente ao estágio dos sete jovens capixabas na Itália, outra ação acontecia no Brasil e seria decisiva para a criação das EFAs no Brasil:

\begin{abstract}
[...] três técnicos italianos, um Economista, um Sociólogo, um Educador, ${ }^{8}$ vinham ao Brasil para analisar a região e a situação local e traçar, juntamente com o jovem Padre Jesuíta, que já tinha regressado ao Espírito Santo, um Plano de Ação concreta na área de atuação dos vigários amigos do Pe. Humberto Pietrogrande, isto é, em 5 municípios capixabas: Anchieta, Alfredo Chaves, Iconha, Piúma e Rio Novo do Sul. Nessa ocasião, o projeto de promoção social foi se especificando em termos de educação, inclusive, de Pedagogia da Alternância no modelo da Escola da Família Agrícola. Lembramos que o técnico em Educação era, na Itália, diretor de uma Escola-Família (NOSELLA, 2013, p. 63-64).
\end{abstract}

Segundo Nosella, criaram-se comitês locais acompanhando o princípio da representatividade o que futuramente se constituiria na criação de uma entidade regional que pudesse dar condições para a implementação das ações desejadas, inclusive, elaboração de projetos e convênios para captação de recursos. No dia 25 de abril de 1968, na Câmara Municipal de Anchieta, constituiu-se o Movimento de Educação Promocional do Espírito Santo (MEPES) com a finalidade de promover a "pessoa humana", com elevação cultural, social e econômica dos agricultores" (NOSELLA, 2013, p. 64).

O plano de ação construído pelos três técnicos italianos elencou como ação prioritária a educação, identificando-a como aquela que iria permear e contribuir para a evolução da pessoa humana em todos os sentidos e, então, a opção clara e visível pela implantação de três Escolas da Família Agrícola (EFAs), que tiveram suas primeiras atividades em 1969 nos municípios de Anchieta, Alfredo Chaves e Rio Novo do Sul (NOSELLA, 2013, p. 66).

Com a criação do MEPES, abriram oportunidades para captação de fundos para manter as EFAs, além do investimento na saúde e na ação comunitária. Observa-se que a construção de um plano de ação metodologicamente projetou a comunidade envolvida para criar algo que pudesse atender as suas necessidades. Apesar do direcionamento e do conhecimento prévio dos técnicos oriundos da Itália, há de se exaltar o fato de terem ido ao encontro da realidade, conhecer e diagnosticar as suas causas principais, para então sugerir e encaminhar as ações pertinentes ocorridas.

As primeiras EFAs só recebiam rapazes, sendo que a primeira escola para moças agricultoras surge em 1971, no município de Iconha (ES). Um ano mais tarde inaugura-se outra EFA feminina, a Escola-Família de Economia Doméstica, no município de São

\footnotetext{
${ }^{8}$ Os dois primeiros, o economista e o sociólogo, atuavam na Itália como professores da Universidade de Padova; já o educador de nome "Mario Zuliani era o Diretor do centro de Promoção Agrícola - CPA de Asolo, situado na província de Treviso [...]. Esse educador, no final de 1968, mudou-se definitivamente para o Brasil, no Estado do ES, ajudando na articulação das atividades que desembocaram nas primeiras EFA's do Brasil" (ZAMBERLAN, 2003, p. 37). É conhecido no Movimento como o primeiro monitor das EFAs do Brasil.
} 
Mateus (ES) (NOSELLA, 2013, p. 66). Para Zamberlan, a expansão do Movimento ocorreu de forma extremamente rápida, surpreendendo aquilo que era planejado inicialmente, fruto do desejo de atender às várias demandas de lideranças e padres. Com isso houve um verdadeiro movimento de pessoas que, em mutirões, conseguiam erguer as construções. $\mathrm{O}$ autor adverte que nesse momento a preocupação maior estava ligada ao fazer, construir fisicamente, e não se priorizava tempo "para planejar conjuntamente o futuro pedagógico e político de cada unidade que foi construída” (ZAMBERLAN, 2003, p. 39-40).

É possível perceber a influência de duas escolas internacionais da Alternância implantadas nas EFAs do estado do Espírito Santo: a estrutura político-administrativa indica marcas principalmente das Escolas-Família italianas; já no aspecto pedagógico, muito se assemelha àquilo que era praticado pelas Maisons francesas. Porém, é interessante ressaltar que as experiências na Itália tiveram um caminho bem diferente da história francesa, como já discutido anteriormente (ZAMBERLAN, 2003, p. 30-31). Outro fator, que acabou impregnando no Movimento da Alternância, é a "pedagogia libertadora de Paulo Freire, influenciando, assim, várias gerações de educadores e educadoras das EFAs do Brasil" (BURGHGRAVE, 2011, p. 132).

Segundo Begnami (2003), é possível perceber quatro fases da implantação e afirmação desse modelo aqui no Brasil: a) a fase da informalidade das escolas; b) a formalização das EFAs; $c$ ) o início da expansão pelo Brasil e; $d$ ) da década de 90 até os dias atuais. Zamberlan (2003, p. 33) também indica quatro fases históricas vivenciadas pelo Movimento: implantação, consolidação, expansão e a articulação nacional em nível políticoinstitucional e pedagógico.

A primeira fase (1969-1972) constitui os passos iniciais, em que são criadas as três primeiras EFAs no ano de 1969: a EFA de Olivânia, a EFA de Alfredo Chaves, e a EFA Rio Novo do Sul. Também em 1970, começa a expansão das EFAs para o norte do estado capixaba, com a criação de EFAs nos municípios de São Mateus, Barra de São Francisco e São Gabriel da Palha. Importante ressaltar que a expansão de EFAs para o norte fez surgir a necessidade do investimento da formação de monitores, motivando a criação do Centro de Formação para Monitores (BEGNAMI, 2003, p. 32).

\begin{abstract}
As primeiras EFAs são escolas informais de "Curso livre", isto é, sem nenhuma autorização legal de órgãos competentes. A duração era de dois anos e o ritmo das alternâncias de uma semana na Escola e duas na família. O público era de jovens rurais, filhos de agricultores familiares. Na maioria, fora da faixa etária escolar, ou seja, jovens com mais de 16 anos de idade. No início houve uma tendência a separar os sexos criando Escolas para moças e rapazes. Essa prática não vigorou, [hoje] as EFAs são mistas (BEGNAMI, 2003, p. 32).
\end{abstract}

Inicialmente o MEPES assume a gestão das escolas em todos os sentidos enquanto mantenedora legal; só depois surgem as associações gestoras de cada EFA, gerenciadas e formadas pelas famílias, o que é hoje um dos princípios que sustenta o sistema EFA. Quando se trata do currículo (Plano de Formação), é possível perceber 
[...] na construção do Projeto do aluno para a sua permanência no campo, utilizando novas tecnologias e recursos; a formação humana e a formação para a cidadania e, sobretudo, uma preocupação com o engajamento sócio-político nas comunidades, movimentos sociais e sindicais, conforme afirmam "os pioneiros" e os relatórios de atividades do Mepes. Os alunos engajavam em "ações comunitárias" quando estavam com a família. Essas ações tinham como objetivos, além da promoção social das famílias camponesas, tornar os alunos líderes em suas comunidades (BEGNAMI, 2003, p. 32).

Apesar dos avanços percebidos pelo novo modelo de escola para o meio rural, as famílias começaram a demandar que as escolas tivessem diplomas escolares, o que ainda não existia. Havia "somente um certificado de 'agricultor técnico"” (BEGNAMI, 2003, p. 33). Outro evento a se considerar é a demanda de alunos de baixa idade pela EFA, o que não era comum àquela época.

Os Instrumentos Pedagógicos praticados tinham destaque central na metodologia pedagógica da Alternância implementada: Plano de Estudo, Caderno da Propriedade e as Visitas às Famílias. Diante da demanda para escolarizar as EFAs, surge então o desafio de como promover o enlace dos conteúdos curriculares exigidos pela estrutura de ensino formal com os Planos de Estudo (BEGNAMI, 2003, p. 33).

A segunda fase histórica (a partir de 1972) concerne-se ao funcionamento das EFAs: continuar na informalidade ou formalizar legalmente as escolas? Buscando alternativas para a demanda dos pais, as EFAs aderiram ao ensino supletivo como saída para a formalização do ensino, tendo em vista que a grande maioria dos alunos tinham idade acima do ideal para o Ensino Fundamental, acima de quatorze anos. A partir de 1972, dão início aos Cursos Supletivos Regulares com as duas primeiras séries, $5^{\text {a }}$ e $6^{\text {a }}$ séries; posteriormente, passaram a trabalhar com as séries finais do Ensino Fundamental ( $5^{\mathrm{a}}$ a $8^{\mathrm{a}}$ séries), em regime de suplência, em três anos, porém sem perder a parte do ensino na agricultura. Dessa forma, o aluno recebia o diploma tão desejado pelos pais com "conclusão do Ensino Fundamental e pré-qualificação profissional em agropecuária” (BEGNAMI, 2003, p. 33).

Ressalta-se que esse processo de escolarização foi uma solicitação dos pais o que se constitui em um marco na história das EFAs, pois, atualmente, é esse o caminho que todas as EFAs do Brasil seguem, tendo a escolarização como direito fundamental dos sujeitos do campo. Com o novo formato curricular, o Plano de Formação das EFAs passou a englobar os fins de "pré-qualificação profissional e escolarização formal". Com a expansão das EFAs dentro do estado do Espírito Santo (ES) e com as exigências do processo de escolarização das escolas, é criado (na primeira metade da década de 70) o Centro de Formação de Monitores em Piúma (ES), constituindo-se numa ferramenta importante para a divulgação da experiência e para a expansão das EFAs, sobretudo fora do estado do ES. Em 1976, é criado o primeiro curso profissionalizante em agropecuária, de ensino médio, na EFA de Olivânia, aumentando o nível de escolarização principalmente para os egressos dos cursos de ensino fundamental (BEGNAMI, 2003, p. 33-34). 
A terceira fase da caminhada histórica das EFAs no Brasil (a partir da segunda metade da década de 70) corresponde ao período da expansão dessas escolas para outros estados, além do Espírito Santo, com duração de aproximadamente uma década (ZAMBERLAN, 2003, p. 41).

A primeira EFA implantada (fora do estado do ES) foi instalada no município de Brotas de Macaúbas no estado da Bahia, em 1975, seguida pela criação da EFA Pe. Augusto Gianda, no estado do Amazonas, em 1976. O movimento da Bahia continuou a se expandir pelo estado, sendo criada posteriormente a Associação Escolas Comunidades Famílias Agrícolas da Bahia - AECOFABA. Segundo Begnami, "A experiência da AECOFABA inaugura uma nova fase na história das EFAs, [...] todas as EFAs nascem com uma associação envolvendo de fato e de direito as famílias nos processos de gestão das escolas, contrapondo o modelo inicial do MEPES" (2003, p. 35).

Segundo o mesmo autor:

A expansão é mais acentuada a partir da segunda metade da década de 1980. Ela ocorre tanto nos Estados onde iniciaram, aumentando o número de unidades, quanto para outros Estados como Minas Gerais, Piauí, Rondônia, Maranhão e Amapá. Na maioria dos casos, as iniciativas de implantação se deram através da pastoral social das igrejas, sobretudo, as Comunidades Eclesiais de Base - CEBs, ligadas à Igreja Católica.

Como consequência dessa fase de expansão, com o intuito de representar todas as EFAs do Brasil, nasce a União Nacional das Escolas Famílias Agrícolas do Brasil (UNEFAB), em 10 de março de 1982, no norte do estado do ES (em São Mateus), tendo sua primeira sede em Anchieta (ES) (Jornal UNEFAB, 1994, 01; apud QUEIROZ, 1997, p. 52). A UNEFAB é criada em um momento de crise de identidade do Movimento das EFAs. Com o processo de escolarização das escolas, como integrar a Pedagogia da Alternância com o sistema de ensino nacional? Fica nítido que há uma imposição do programa oficial de ensino do país, não respeitando "as especificidades de um sistema de educação por alternância, gerando com isto, incertezas, inseguranças, entre outros” (BEGNAMI, 2003, p. 37).

A quarta e última etapa perpassa historicamente os últimos 25 anos desse modelo educacional (1990 - 2015). Segundo Begnami, o Movimento das EFAs brasileiras traz, nas suas lutas na década de 90, três pontos de pauta, na tentativa de dar novo ânimo ao Movimento nacional: “a) a necessidade do fortalecimento institucional [...], com a retomada da UNEFAB em 1992. b) a implementação e fortalecimento das Associações Regionais e locais. c) a adequação da formação ao mundo rural que sofre mudanças com as políticas da globalização excludente" (BEGNAMI, 2003, p. 37-38).

Foi só a partir dos anos 90 que a UNEFAB começou a encontrar algum sentido à frente do Movimento nacional das EFAs, após viver um tempo de "crise institucional" desde a sua criação. Inicia-se uma fase de articulação nacional integrando os diversos grupos e regionais do Brasil. "É uma fase em que a Diretoria da UNEFAB intensifica os contatos e articulações, em nível nacional e regional, para melhorar os aspectos associativos, em vista 
da ampliação do poder político das Associações". Como possibilidade desse fortalecimento associativo, a formação dos atores foi apontada como saída, sendo estruturados dois tipos de formação: formação das famílias das EFAs e formação inicial dos monitores nas regionais, com a orientação da Equipe Pedagógica Nacional - EPN (ZAMBERLAN, 2003, p. 45).

Segundo Menezes, a realização em 1998 da VII Assembleia Geral da UNEFAB em Teófilo Otoni (MG) "se constituiu num marco na oficialização dessas mudanças". Uma das mudanças com grande relevância se deu na eleição da nova diretoria, em que ocorreu uma ampliação do número de agricultores no Conselho Administrativo (pelo menos dois terços), sendo o presidente da União Nacional "obrigatoriamente agricultor". Um parceiro importante para o desenvolvimento dessas ações é a Solidariedade Internacional dos Movimentos de Formação Rural (SIMFR). Essa cooperação começou em 1993, possibilitando uma aproximação das EFAs do Brasil com as MFRs da França, por meio de "seminários, congressos, cursos de formação de formadores e de dirigentes de associações, elaboração de materiais didáticos, livros, entre outros". Contando com o apoio da EPN, as formações passam a ser organizadas de forma regionalizada (MENEZES, 2013, p. 78-79).

Dentre as ações financiadas pela entidade belga, destacavam-se a Formação Pedagógica Inicial de Monitores e Assessoria Pedagógica in loco às EFAs, através de programas de desenvolvimento institucional, com início nos anos 90 até o fim da década passada. Em 2013, o apoio da SIMFR às regionais estava no último programa e se restringia apenas ao custeio de $80 \%$ do salário do coordenador pedagógico de cada regional e a algumas ações da UNEFAB, tal como, o funcionamento da EPN.

\section{Panorama atual dos Centros Familiares de Formação por Alternância (CEFFAs) no Brasil}

Os dados utilizados para descrever um panorama mais atual considerou dados de pesquisa até o ano de 2015, a utilização do termo CEFFA se refere a todos os projetos educativos que utilizam a Alternância no Brasil, ainda que o nosso foco seja as EFAs. Em junho de 2013, foi realizada uma pesquisa no âmbito dos CEFFAs atendendo ao Edital Público n. 07/13 do Ministério da Educação (MEC), através da Secretaria de Educação Continuada, Alfabetização, Diversidade e Inclusão (SECADI). Apesar da pesquisa focar apenas as escolas que trabalham com o Ensino Médio e Técnico, nos ajuda a fazer uma amostra sintética do panorama atual das Escolas de Alternância no Brasil, considerando apenas as denominações Escolas Famílias Agrícolas (EFAs), Escolas Comunitárias Rurais (ECORs) e Casas Familiares Rurais (CFRs).

A pesquisa, de abordagem quantitativa, permite apontar um quadro geral da dimensão desse Movimento, mas não dá conta de aprofundar na complexidade qualitativa em que se inserem os CEFFAs. Mesmo assim, entendemos ser um avanço no sentido de potencializar dados que propõem estratégias para ampliar o seu acesso às políticas públicas, delineando possibilidades para o fortalecimento da agricultura familiar camponesa no Brasil. 
Em 2013, foram contabilizadas 264 unidades educativas9 (considerando o nível de Ensino Fundamental e Médio), com aproximadamente 21.000 estudantes matriculados, ultrapassando cerca de 18.000 famílias associadas. Ao todo são ofertados 329 cursos, sendo 189 do Ensino Médio e Profissionalizante, 132 do Ensino Fundamental (séries finais), 2 de pós-médio e 6 cursos de qualificação (BEGNAMI, 2013, p. 20).

Percebe-se um número menor de famílias em comparação à quantidade de estudantes, isso se explica pela existência de irmãos estudando juntos. Percebemos também um número maior de cursos do Ensino Médio Profissionalizante, que coincide com um momento de relevante valorização no Brasil da educação profissional naquele ano. A maioria dos cursos se dá na área técnica de agropecuária, abrangendo 68\% dos cursos de forma geral. Outros cursos são oferecidos pelos CEFFAs de forma diversa: Agroecologia, Administração rural, Zootecnia, Gestão Ambiental, Recursos Naturais, Serviços de Restaurante e Bar, Meio Ambiente, Alimentos, Agroindústria, Agricultura e Produção Agrícola familiar (BEGNAMI, 2013, p. 21).

Considerando o número de CEFFA em 2013 (264 unidades) e o número de 145 Centros registrados no estudo de Moreira (2000, p. 75), podemos perceber um aumento considerável de 119 CEFFAs, ou seja, 82,06\% no Brasil, em 13 anos. A perspectiva é que essa percentagem tenda a crescer mais ainda nos próximos anos, principalmente com o incentivo de programas governamentais e leis aprovadas na Educação do Campo. Este panorama deverá ser atualizado em breve, já que em janeiro de 2018, o Ministério da Educação (MEC) publicou EDITAL Nº 01/2018 para contratação de consultou com vistas a com vistas a subsidiar a SECADI na atualização das ações de formação inicial e continuada de professores e demais profissionais da educação do campo.

Por fim, é importante destacar que mesmo com grandes avanços ao longo da história das EFAs, ainda há desafios cruciais para o futuro desta prática educativa da Educação do Campo. Com base em investigação realizada no Vale do Jequitinhonha (MG) por Freitas (2015), que garantimos não destoar tanto das demais regiões brasileiras, podemos apontar pelo menos quatro desafios que comprometem o trabalho das EFAs/CEFFAs: a) continuidade da oferta da formação dos monitores, responsáveis pela condução do processo de ensino-aprendizagem através da Alternância; $b$ ) a sobrecarga de trabalho enfrentada por esses educadores em função das equipes reduzidas, considerando a quantidade de demandas encontradas para o funcionamento das escolas; $c$ ) a gestão do tempo do monitor no cotidiano da EFA e; $d$ ) financiamento aquém das necessidades para a manutenção da EFA

Este último desafio é uma das causas principais dos problemas anteriores enfrentados, já que para valorização profissional e formação é preciso contar recursos adequados e disponíveis. Considerando o cenário político e financeiro a que passa o Brasil na atualidade, tais necessidades têm se intensificado ainda mais, colocando em cheque todo um processo histórico de construção como vimos ao longo do texto, comprometendo

\footnotetext{
${ }^{9}$ Desse total, 32 unidades são encontradas na Bahia (BEGNAMI, 2011).
} 
significativamente a sua prática pedagógica e as perspectivas de futuro dos povos da agricultura familiar camponesa.

\section{Considerações Finais}

A descrição histórica apresentada neste artigo evidencia a construção de um projeto educativo para o campo, nascida a partir de experiências e de necessidades reais de agricultores familiares da França, Itália e Brasil. Também mostra que esse caminho não se finalizou, é um processo dinâmico e em constante aprimoramento junto a seus sujeitos. Não nasceu de uma mente brilhante, de um intelectual. Foi construído sobretudo com o protagonismo da participação das famílias. Neste sentido apresenta uma alternativa inovadora e revolucionária. Quando que se viu na História da Educação Brasileira uma proposta em que agricultores familiares (muitas das vezes analfabetos) estiveram tanto na condução de um projeto educacional?

Por outro lado, percebemos um tema complexo que deve ser mais aprofundado, o que não é possível apenas lendo este texto. A abrangência das Escolas Famílias Agrícolas nos mostra uma marca histórica deste modelo de educação no contexto da Educação do Campo, abrindo um espaço político para a luta pelos direitos dos povos do campo, negados ao longo de sua história. A Alternância tem ganhado espaço nesse cenário, inclusive no ensino superior com as Licenciaturas em Educação do Campo, cursos de especializações e mestrado em universidades brasileiras, utilizando o Regime da Alternância como metodologia de ensino.

Decorrente deste processo histórico, encontramos também vários marcos legais não elencados neste texto, como o Parecer 01/2006 do Conselho Nacional de Educação, que reconhece os dias da Pedagogia da Alternância como letivos e o Decreto presidencial 7.352/2010, que dispõe sobre a política de educação do campo e o Programa Nacional de Educação na Reforma Agrária - PRONERA. No entanto, ainda há desafios fundantes para a continuidade das EFAs, principalmente pela ausência de financiamento seguro e adequado dessas escolas pelo Governo e sociedade, o que interfere negativamente na qualidade do trabalho prestado, como nas condições de trabalho e formação dos seus educadores/monitores.

Devemos enaltecer o fato de que o Movimento das EFAs, mesmo enfrentando as adversidades de sobreviver em um país capitalista sem recursos garantidos, é capaz de criar alternativas e de construir projetos diferenciados para a formação dos jovens do campo. Sem dúvidas, a construção sólida de sua história tem sido importante para a superação dos desafios e seguir fortalecendo a Escola Família Agrícola, a Pedagogia da Alternância, dispondo assim de um projeto seguro e atraente para a educação dos adolescentes e jovens do campo.

\section{Referências}

Revista Educação e Ciências Sociais, Salvador, v.1, n.1, 2018. 
BEGNAMI, João B. Os CEFFAs e a Educação Média e Profissional Integrada. Texto elaborado para a Equipe Pedagógica Nacional dos CEFFAs do Brasil. Brasília: Rede dos CEFFASs/UNEFAB?ARCAFAR SUL/ARCAFAR NE/No, setembro de 2011. $24 \mathrm{f}$.

BEGNAMI, João Batista (consultor). Estudo Sobre o Funcionamento dos Centros Familiares de Formação por Alternância no Brasil - CEFFAs. Edital Público n. 07/13 SECADI/MEC - Projeto 914BRZ1367. Brasília: Ministério da Educação, Secretaria de Educação Continuada, Alfabetização, Diversidade e Inclusão - SECADI, Departamento De Educação Para A Cidadania Diversidade e Inclusão, Coordenação Geral de Educação do Campo, junho de 2013.

BEGNAMI, João. B. Formação pedagógica de monitores das Escolas Famílias Agrícolas e alternâncias. Um Estudo Intensivo dos Processos Formativos de cinco Monitores. Dissertação de Mestrado em Ciências da Educação - Universidade de Nova Lisboa, Portugal, 2003. 318f.

BURGHGRAVE, Thierry de. Autoformação e participação no meio sócio-profissional: abordagem biográfica de dois agricultores do Movimento das Escolas Famílias Agrícolas. Dissertação de Mestrado em Ciências da Educação - Universidade de Nova Lisboa, Portugal, 2003. 220f.

BURGHGRAVE, Thierry de. Vagabundos, não senhor: cidadãos brasileiros e planetários! Uma experiência educativa pioneira do campo. Orizona (GO): União Nacional das Escolas Famílias Agrícolas (UNEFAB), 2011.

CALVÓ, Pedro P. A vitalidade do movimento dos CEFFA. In: GARCÍAMARIRRODRIGA, Roberto \& CALVÓ, Pedro P. Formação em Alternância $e$ Desenvolvimento Local: o movimento educativo dos CEFFA no mundo. Belo Horizonte (MG): O Lutador, 2010. p. 109- 134.

FREIRE, Paulo. Educação como prática da liberdade. 19ª ed. Rio de Janeiro: Paz e Terra, 1989.

FREITAS, Gilmar V. Formação em Pedagogia da Alternância: um estudo sobre os processos formativos implementados pela AMEFA junto aos monitores das EFAs do Médio Jequitinhonha-MG. Dissertação de Mestrado em Educação do Campo - UFRB, AmargosaBA, 2015.

GARCÍA-MARIRRODRIGA, Roberto. Os CEFFA, uma Iniciativa das Famílias Rurais: a primeira experiência de CEFFA no mundo. In: GARCÍA-MARIRRODRIGA, Roberto \& CALVÓ, Pedro P. Formação em Alternância e Desenvolvimento Local: o movimento educativo dos CEFFA no mundo. Belo Horizonte (MG): O Lutador, 2010. p. 21-56.

GIMONET, Jean-Claude. Nascimento e Desenvolvimento de um Movimento Educativo: as casas familiares rurais de educação e de orientação. In: Alternância e Desenvolvimento. Salvador (BA): União Nacional das Escolas Famílias Agrícolas do Brasil (UNEFAB), 1999, p. $39-48$.

MENEZES, Rachel R. As Escolas Comunitárias Rurais no Município de Jaguaré: um estudo sobre a expansão da pedagogia da alternância no estado do Espírito Santo/Brasil. 
Dissertação de Mestrado em Educação da Universidade Federal do Espírito Santo (UFES), Vitória (ES), 2013. 172f.

NOSELLA, Paolo. Origens da Pedagogia da Alternância no Brasil. Vitória (ES): Editora da Universidade Federal do Espírito Santo (EDUFES), 2013.

PESSOTI, Alda L. Escola da Família Agrícola: uma alternativa para o ensino Rural. Dissertação de Mestrado em Educação. Rio de Janeiro: Fundação Getúlio Vargas (FGV), 1978. $195 f$.

QUEIROZ, João B. P. O processo de implantação da Escola Família Agrícola (EFA) de Goiás. Dissertação de Mestrado em educação - Goiânia-Go: Universidade Federal de Goiás, 1997. $277 f$.

WEFFORT, Francisco C. Educação e Política: reflexões sociológicas sobre uma pedagogia da liberdade. In: FREIRE, Paulo. Educação como prática da liberdade. $19^{\mathrm{a}}$ ed. Rio de Janeiro: Paz e Terra, 1989, p. 02-26.

ZAMBERLAN, Sergio. "O Lugar da Família na Vida Institucional da Escola-Família": participação e relações de poder. Dissertação de Mestrado em Ciências da Educação Universidade de Nova Lisboa, Portugal, 2003. 191f. 